tions clinicians have adopted a more selective EEG requesting policy. Doctors may have a lower risk of making, and patients may have lower risk of receiving, a misdiagnosis of epilepsy. The reduction in the number of unnecessary procedures releases technical capacity which can be used in the conduct of other investigations. Systematic replication of this work, possibly on a regional basis, would yield savings which would permit development of accessible local neurophysiology services.

Julie Jones and Clare Jowett in the audit departments of Wrexham Maelor and Royal Shrewsbury Hospitals facilitated the meetings and distribution of guidelines. We specially thank the users of the service for listening and changing their practice

Contributors: DS had the original idea for the audit, helped with data collection and analysis, and is guarantor for the study. $\mathrm{RB}$ did most of the data collection. RP reported on all the EEGs.

The paper was jointly written by DS, RB, RP, and BT.

Funding: None.

Competing interests: DS presented the data at an educational meeting sponsored by GlaxoWellcome, for which he received payment

1 Fowle AJ, Binnie CD. Uses and abuses of the EEG in epilepsy. Epilepsia 2000:41(suppl 3):10-8.

2 Commission on classification and terminology of an international league against epilepsy. Proposal for classification of epilepsies and epileptic syndromes. Epilepsia 1989;30:389-99.
3 King MA, Newton MR, Jackson GD, Fitt GJ, Mitchell LA, Silvapulle MJ, et al. Epileptology of the first seizure presentation; a clinical, electroencephalographic and magnetic resonance imaging study of 300 consecutive patients. Lancet 1998;352:1007-11.

4 Binnie CD, Prior PF. Electroencephalography. J Neurol Neurosurg Psychia try 1994;57:1308-19.

5 Berg AT, Shinnar S. The risk of recurrence following a first unprovoked seizure. Neurology 1991;41:965-72.

6 MRC Antiepileptic Drug Withdrawal Study Group. Prognostic index for recurrence of seizures after remission of epilepsy. BMJ 1993;306:1374-8.

7 Binnie CD. Electroencephalography. In: Laidlaw J, Richens A, Chadwick D, eds. A textbook of epilepsy. 4th ed. Edinburgh: Churchill Livingstone,1992:277-8.

8 Ajmone-Marsan C, Zivin LS. Factors related to the occurrence of typical paroxysmal abnormalities in the EEG records of epileptic patients. Epilepsia 1970;11:361-81.

9 Bridgers SL. Epileptiform abnormalities discovered on electroencephalographic screening of psychiatric in-patients. Arch Neurol 1987;44:312-6.

10 Gregory RP, Oates T, Merry RTG. Electroencephalogram epileptiform abnormalities in candidates for aircrew training. Electroencephalogr Clin Neurophysiol 1993;86:75-7

11 Riley TL. Normal variants in EEG that are mistaken as epileptic patterns. In: Gross M, ed. Pseudoepilepsy. Lexington KY: Heath, 1983:25-7.

12 Nicolaides P, Appleton RE, Beirne EM. EEG requests in paediatrics: an audit. Arch Dis Child 1995;72:522-3.

13 Binnie CD. EEG audit: increasing cost efficiency of investigations in epilepsy. Electroencephalogr Clin Neurophysiol 1990;76:29P.

14 Gibbs J, Appleton RE. False diagnosis of epilepsy in children. Seizure 1992;1:15-8.

15 Smith D, Dafalla B, Chadwick DW. The misdiagnosis of epilepsy and the management of refractory epilepsy in a specialist clinic. QJ Med 1999; $15-23$.

(Accepted 14 February 2001)
In contrast to North America and Australia, little attention has been paid to the use of health services by adolescents in the United Kingdom. The incidence of survival from chronic illness in young people is increasing. The care of adolescents is becoming a quality issue for the NHS. ${ }^{12}$ Health data are rarely available in the United Kingdom on adolescents as a separate group, with standard data dividing young people into those aged under 14 years or those aged 15-44 years. ${ }^{3}$ A study of the use of psychiatric beds by adolescents in England and Wales is presently being undertaken by the Royal College of Psychiatrists (A O'Herlihy, personal communication). Previous regional studies have been undertaken, ${ }^{45}$ but reliable national data to guide the provision of other hospital services to adolescents are not available.

\section{Participants, methods, and results}

I requested information on the numbers of hospital bed days of inpatients and day case patients aged 12 to 19 years from April 1997 to March 1998 from all health authorities and boards in Wales and Scotland and 27 randomly selected ones from England. I excluded admissions for obstetrics, mental health, and learning disabilities. Information was provided by 37 health authorities and boards (response rate 79\%), including three of the five in Wales, all 15 health boards in Scotland, and 19 English health authorities and boards, including at least one from each of the eight English regions. Information from three health authorities and boards was unusable. Average bed days was calculated by summing data from all 34 included health authorities and boards (population 15.8

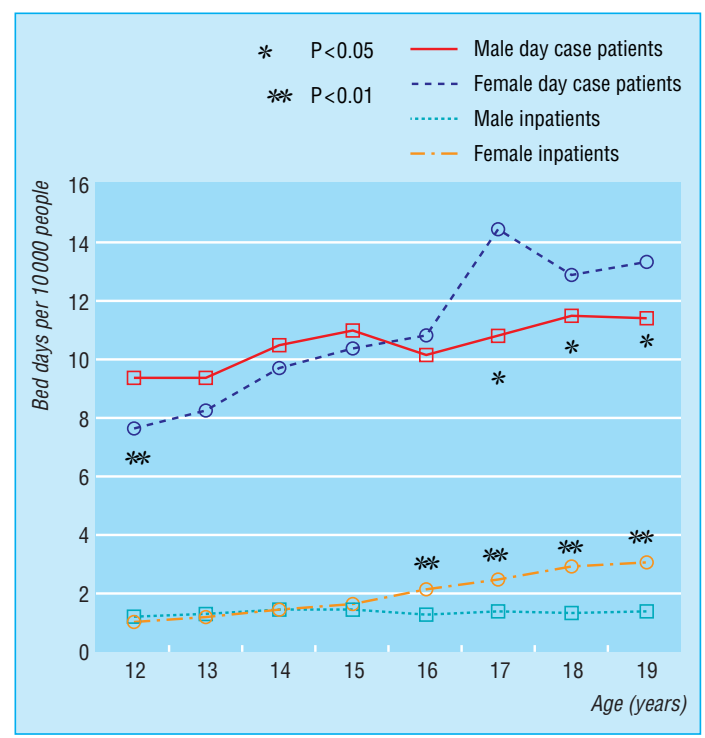

Bed days of adolescent inpatients and day case patients per 10000 population by age and sex
Editorial by Macfarlane and Blum

Department of Medicine, University College London, London W1T 3AA

R M Viner adolescent medicine and endocrinology R.Viner@ich. ucl.ac.uk

BMJ 2001;322:957-8 
million). I used two sample $t$ tests to analyse differences in means. Data were normally distributed.

Total inpatient bed days per 10000 people increased significantly from $17.0(\mathrm{SD} 7.4)$ at 12 years to 24.6 (SD 7.7) at 19 years $(t=-4.5, \mathrm{P}<0.000)$ (figure). Bed days for males were significantly higher than females at age 12 years; however, bed usage by females surpassed that of males from 17 years. Bed days for females but not males increased significantly during adolescence. Total bed days of day cases per 10000 people increased significantly from 2.32 (SD 1.82) at 12 years to 4.31 (SD 1.38$)$ at 19 years $(t=-6.8, \mathrm{P}<0.000)$. I found no increase in bed days of male day cases during adolescence, however in females bed days increased significantly between 12 and 19 years. Females used significantly more bed days as day cases than did males from 16 years onwards. Bed day usage (inpatient and day case) was not related to the population of the health authority.

Data from all Scottish health boards (population 5.2 million) allowed calculations of the use of inpatient beds per 10000 people of a specific age. Bed day use increased significantly from 1604.2 (SD 100.5) per 1000012 year olds to 2099.4 (SD 82.1) per 10000 19 year olds $(t=-3.4, \mathrm{P}<0.005)$. I found no significant differences between sexes. Total inpatient bed use was 3732.5 per 10000 young people aged 12-19 years.

\section{Comment}

Adolescents aged 12 to 19 years occupy an average of 18 inpatient beds and 2.2 day case beds in a district general hospital nominally serving 250000 people. The use of hospital beds increases rather than decreases through adolescence. This contradicts the assumption that adolescents use hospitals rarely and do not merit separate facilities. An average district general hospital has the activity to support a ward for adolescents of 12 to 15 beds. Overall, 12.8 inpatient beds are required for each 10000 adolescents aged 12 to 19 years in the hospital catchment area (based on standard assumptions of an $80 \%$ bed occupancy). Although dedicated wards for adolescents may not be possible in many hospitals, the provision of other facilities should be considered.

Funding: None.

Competing interests: None declared.

1 Viner R. Transition from paediatric to adult care. Bridging the gaps or passing the buck? Arch Dis Child 1999;81:271-5.

2 House of Commons Select Committee on Health. The specific health needs of children and young people: House of Commons Select Committee on health, fifth report of session 1996-96. London: Stationery Office, 1997:xl.

3 Health and personal social services statistics for England. London: Stationery Office, 1999.

4 British Paediatric Association. Report of the working party on the needs and care of adolescents. London, BPA, 1985.

5 Henderson J, Goldacre M, Yeates D. Use of hospital in patient care in adolescence. Arch Dis Child 1993;169:559-63.

(Accepted 18 December 2000)

\title{
Anaemia in Chinese, South Asian, and European populations in Newcastle upon Tyne: cross sectional study
}

\author{
Colin Fischbacher, Raj Bhopal, Sheila Patel, Martin White, Nigel Unwin, K G M M Alberti
}

Department of Epidemiology and Public Health, Medical School, University of Newcastle, Newcastle upon Tyne NE2 4HH

Colin M

Fischbacher

lecturer in public

health medicine

Sheila Patel

research associate

Martin White

senior lecturer in

public health

Nigel Unwin senior lecturer in epidemiology

Department of Diabetes, Medical School, University of Newcastle K G M M Alberti professor of medicine continued over

BMJ 2001;322:958-9
Britt drew attention to anaemia in Punjabi women in Southall nearly 20 years ago. ${ }^{1}$ Representative population data on anaemia in adults from ethnic minorities in the United Kingdom have not been published since then. We used data from the Newcastle heart project ${ }^{23}$ to assess the prevalence of anaemia in South Asian (Indian, Pakistani, and Bangladeshi) and Chinese ethnic groups.

\section{Methods and results}

The Newcastle heart project was a stratified random sample of 1889 Newcastle residents of European $(\mathrm{n}=825)$, Indian (259), Pakistani (305), Bangladeshi (120), and Chinese (380) ethnic origin, studied during 1991-7. Chinese respondents were aged 25-64 years; the others were aged 25-74 years. Full details have been published elsewhere. ${ }^{2}{ }^{3}$ Haemoglobin and red cell indices were determined with a Coulter STKS analyser. We defined anaemia as a haemoglobin $<130 \mathrm{~g} / 1$ in men and $<120 \mathrm{~g} / \mathrm{l}$ in women. We compared respondents who ate beef, pork, lamb, chicken, or fish with those who rarely or never did. Women were asked about their menstrual history, though this information was not available for Chinese respondents. Odds ratios were estimated from logistic regression using Stata 6.0 (Stata Corporation, College Station, TX).

Haemoglobin was lowest in men of European origin and highest in those of Chinese origin, whereas haemoglobin was lower in South Asian and Chinese women than in European women (table). The prevalence of anaemia was similar among men of all ethnic groups. However, anaemia was $3.0 \quad(95 \%$ confidence interval 2.0 to 4.4) times more prevalent in South Asian women than in European women and 2.1 (1.3 to 3.3) times more prevalent in Chinese women than in European women. The findings were similar when the analysis was confined to non-smokers. One per cent $(0.3 \%$ to $2.6 \%)$ of European women and $4.0 \%$ (2.2\% to $6.6 \%)$ of South Asian women had haemoglobin $<100 \mathrm{~g} / \mathrm{l}$. Anaemia was less prevalent after the menopause in European women but remained common after the menopause among Indian and Bangladeshi women.

Of Indian respondents, $32 \%$ rarely or never ate meat compared with less than $2 \%$ of other ethnic groups. Among Indian respondents, 23\% of those who did not eat meat and 13\% of those who did were anaemic. The numbers who did not eat meat were too small for analysis by any other ethnic group. The odds 